\title{
Shadow Prices for Pakistan: An Assessment of Alternative Estimates
}

\author{
ISABELLE TSAKOK*
}

\section{INTRODUCTION}

Recently, there have been four attempts to estimate shadow prices for Pakistan. These are (i) Squire et al. [5], (ii) Guisinger [1], (iii) Khan [2], and (iv) Weiss [7]. ${ }^{1}$ The aim of this paper is to assess these alternative estimates in terms of their usefulness for the economic analysis of policies and projects in Pakistan.

As the study titles indicate, each study pursues a somewhat different aim, although there is substantial overlapping in the parameters considered and the data used in their computation. The SLD study is an attempt to apply shadow pricing methodology to macro policy issues. To do so, it estimates specific parameters, but its primary objective is not to produce a detailed and comprehensive set of shadow prices. The SG study is a lengthy commentary on the methodology and data used by Squire-Little-Durdag [5], in terms of their adequacy for policy analysis in Pakistan. Whereas both Squire-Little-Durdag and Guisinger [1] estimate social prices, Khan's analysis [2] is purely in terms of efficiency prices. In this study, Khan estimates the shadow discount rate, also known as the shadow price of capital and the shadow wage of unskilled labour. He is primarily concerned with project evaluation, not policy evaluation. Like Khan, Weiss [7] is concerned with project evaluation. However, he approaches the task from a different angle: the derivation and use of income weights in project appraisal.

\section{EVALUATION OF ALTERNATIVE ESTIMATES}

The main results of these studies are presented in a schematic form in Table 1. It will be seen from the Summary of Comments given in that table that all the esti-

*The author is an Economist at the World Bank. The views expressed here are those of the author and may not be shared by the management of the Bank.

Stephen Guisinger's article, published in the Summer 1979 issue of this journal, similarly expressed personal views of the author and not necessarily of the World Bank. (Editor)

${ }^{1}$ These four studies will be respectively referred to in the following abbreviated forms (i) SLD; (ii) SG; (iii) ZK; and (iv) JW. 
Table 1

An Assessment of the Main Results of

Squire-Little-Durdag [5] S. Guisinger [1]

\section{Traditional Efficiency}

Approach

1. Standard Conversion

Factor (SCF)

SLD

II. Consumption Conversion Factor (CCF or B)

III. Opportunity Cost of Capital (q)

IV. Shadow Wage Rate/Market Wage Rate (SWR)/(MWR)

New Efficiency Approach

$\mathrm{n}=$

$\mathrm{n}=2$

$\mathrm{n}=1$

$\mathrm{n}=2$

IV. $\frac{\text { SWR }}{\text { MWR }}$

(A) Skilled and semi-skilled
artisans
(i) Short run
1.05
.45
1.05

(B) Unskilled

\begin{tabular}{|c|c|c|}
\hline (i) Rural & .75 & .65 \\
\hline (ii) Urban & .80 & .75 \\
\hline (iii) Public & .65 & .55 \\
\hline
\end{tabular}

\section{National Parameters in Different Studies}

\begin{tabular}{|c|c|c|}
\hline J. Weiss [7] & Z. Khan [2] & Summary of Comments \\
\hline JW & ZK & \\
\hline .91 & .948 & $\begin{array}{l}\text { Needs revision. Reason: out- } \\
\text { dated data base. }\end{array}$ \\
\hline .98 & & $\begin{array}{l}\text { Needs revision. Reason: out- } \\
\text { dated data base. These esti- } \\
\text { mates are not comparable. } \\
\text { SLD's apply on a nationwide } \\
\text { basis; JW's apply only to un- } \\
\text { skilled labour. }\end{array}$ \\
\hline \multirow[t]{2}{*}{$.10-.12$} & $.14-.15$ & $\begin{array}{l}\text { SLD's and SG's estimates } \\
\text { contain social analysis but } \\
\text { are listed here for conven- } \\
\text { ience. These four estimates } \\
\text { are not comparable because } \\
\text { they do not refer to the } \\
\text { same capital stock. }\end{array}$ \\
\hline & $\begin{array}{l}.31-.46(1971) \\
.32-.47(1975)\end{array}$ & $\begin{array}{l}\text { These measure the oppor- } \\
\text { tunity cost of expanding de- } \\
\text { mand for unskilled labour in } \\
\text { rural areas. These estimates } \\
\text { will soon be superseded by } \\
\text { more recent estimates from } \\
\text { the ongoing Study on } \\
\text { Labour Migration from Paki- } \\
\text { stan to Middle East. }\end{array}$ \\
\hline $\mathrm{n}=1$ & & \\
\hline
\end{tabular}

Needs revision. More current estimates will be available through the ongoing Study on Labour Migration. Furthermore, SG questions the basic formulation of the shadow prices of Categories A (i) and (ii). 
Squire-Little-Durdag [5] S. Guisinger [1]

V. Consumption Rate of

Interest (CRI)

$03(\mathrm{p}=0)$

.04

$04(\mathrm{p}=1 \%)(\mathrm{p}=3 \%)$

VI. Consumption Distribution

Parameter (n)

VII. Critical Consumption

$\begin{array}{lll}\text { Level (CCL) } & \mathrm{CCL}=\overline{\mathrm{C}} \text { at } & \frac{\mathrm{d}}{\mathrm{v}}=.8 \\ \frac{\mathrm{d}}{\mathrm{v}}=.8 & \end{array}$

J. Weiss [7]

.06

VIII. Value of Public Income (v) (relative to average

consumption)

1.2

Value of Public Invest-

ment (relative to

1.0

Value of Public Curren

Expenditure (relative to

average consumption)

IX. Accounting Rate of Interest (ARI)

Z. Khan [2]

Summary of Comments

Little objective basis on which to judge alternative estimates.

SLD and JW experiment with alternative values of $n$. SLD recommend $\mathrm{n}=2$ for policy analysis but, in fact, argue that $\mathrm{n}=1$ is more consistent with Draft Plan.

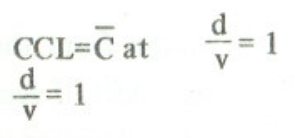

$1.3-2.0 \quad 1.8-2.8$
The difference in values of $\mathrm{d} / \mathrm{v}$ at $\mathrm{CCL}=\overline{\mathrm{C}}$ between SLD and JW lies in their differing CCF. For simplicity, JW assumes CCF $=1$. Both need revision.

Problems with the data base used undermine the validity of $v$. Needs revision.

These estimates are not comparable because (1) the underlying estimate of $\mathrm{q}$ is not comparable (see III above); (2) while SLD's, SG's and JW's estimations involve social analysis, ZK's does not; (3) finally, there is very little objective basis to decide between the CRI which enters in the estimates from SLD and SG (see V above). 
mates need revision (before they can be used in decision making) although the reasons differ for the various specific estimates with the particular (i) structure of the estimation formula employed; (ii) data base used for computation and (iii) assumptions resorted to as data deficiencies are encountered. With respect to (i), the structure of the estimation formula may not capture the appropriate concept or variable. This is a problem with the estimation of the opportunity cost of capital $q$ the value of public income $v$, and therefore also the crucial parameter, the accounting rate of interest ARI. With respect to (ii) and (iii), recent policy shifts and data availability render the estimation of several parameters, such as the shadow exchange rate (SER), the consumption conversion factor (CCF or B) and the shadow wage of labour (SWR), of questionable value.

Furthermore, the policy implications which follow from these studies differ markedly. In particular, the SLD estimates of $q, v$ and ARI, if accepted, are indicative of a low level of productivity of public investment. A major implication would then be the undesirability of Government borrowing from either private or foreign sector on commercial terms. The SG estimates lead to a higher ARI of 7.3 - 8.3 percent. If these estimates are accepted, then the verdict on commercial borrowing by the Government will not be so severe.

Given the importance of the ARI, a substantial part of the evaluation will be devoted to it. For easy reference, the formula for the ARI is given below:

$$
A R I=C R I-\frac{d v}{d t} \cdot \frac{1}{v} \text {. }
$$

where $\quad$ RI $=n g+p$

$$
\begin{aligned}
& \mathbf{v}=\frac{\mathrm{q}}{\mathrm{CRI}} \cdot \mathrm{B} \cdot \text { or } \\
& \mathrm{v}=\frac{[\mathrm{q}-\mathrm{sq}]}{[\mathrm{CRI}-\mathrm{sq}]} / \mathrm{B} \\
& \mathrm{q}=\text { opportunity cost of capital } \\
& \mathrm{s}=\text { marginal propensity to reinvest out of profits } \\
& \mathrm{B}=\text { Consumption Conversion Factor }
\end{aligned}
$$

\section{PARAMETER-BY-PARAMETER EVALUATION OF ARI}

\section{The Value of CRI}

SLD and SG have estimated the consumption rate of interest and their differing estimates and assumptions are listed below:

SLD's Estimate $=1.5-4.0 \%$
\[ \begin{aligned} & \text { Best Estimate: } 3.0 \% \\ & \text { Assumptions: } \mathrm{n}=2 \\ & \mathrm{~g}=1.5 \\ & \mathrm{p}=0\end{aligned} \]

See $[5$, pp. 92-93].

$$
\begin{aligned}
& \text { SG's Estimate = } \begin{aligned}
&=5-5.5 \% \\
& \text { Assumptions: } \mathrm{n}=1 \\
& \mathrm{~g}=3 \\
& \mathrm{p}=1.5 \text { to } 2.0 \%
\end{aligned}
\end{aligned}
$$

See [1, pp. 120 and 125].

An entirely objective assessment of the relative merits of each estimate is not possible since both $\mathrm{n}$, the social elasticity of the marginal utility of consumption, and $\mathrm{p}$, the rate of pure time preference, are subjective.

The JW study also makes this point [7, pp. 155-156]. On g, Guisinger argues that the SLD data are both "too short and too unrepresentative of the past and future patterns of real per capita growth" [1, p. 119]. Are the growth rates of the Sixties more representative of the future growth rates for Pakistan? Only the future can tell. The 1972--77 period has been fairly stagnant but growth has improved in recent years.

\section{The Value of $q$}

In their Working Paper, Squire-Little-Durdag obtain an estimate of 6 percent for q [6, Appendix p. 18]. This low figure is markedly different from Guisinger's 15 percent [1, p. 125], Khan's $14-14.5$ percent [2, p. 137], and Weiss's $10-12$ percent [7, p. 158].

These differences are in fact not surprising given the fact that these estimates do not refer to the same capital stock. The SLD study uses public expenditure data in the industrial sector, while the SG study uses data from large-scale manufacturing sector as a whole. Khan [2] uses data on pre-tax profits net of depreciation in the industrial sector and the social rates of return of certain projects in agriculture. The JW study does not give much rationale for its choice of figures except that they are considered reasonable after discussion with the Government [7, p. 156, footnote 17].

Since these estimates refer to different capital stocks, the methods of computation also differ. The SLD Staff Working Paper [6] uses data on pre-tax profits and 
interest payment for FY '74-'76 to calculate return to capital for FY '75. They manipulate data on the book value of fixed assets, on depreciation and on inflation rates to arrive at the replacement cost of the stock of capital in FY '75. Guisinger [1] argues with some specifics of the SLD calculation procedure and points out that the estimate contains both upwards and downwards biases. However, Guisinger does not state whether, on balance, the bias is up or down.

Guisinger's main argument against the SLD calculation seems to be in the choice of the Board of Industrial Management (BIM) data. Looking primarily at firms under the BIM is likely to bias q downwards, since these firms are not representative of the large-scale industry. SG uses instead the Gross Census Value Added (GCVA) for large-scale manufacturing 1975-76 from the Census of Manufacturing Industries (CMI). However, if $\mathrm{q}$ is to measure the productivity of public investment, the SLD choice seems to be more appropriate than the SG choice. It seems that the wider the data base, the more favourable the q. While SG attempts to measure $q$ for large-scale manufacturing, ZK tries to capture an economy-wide q. He obtains 1975-76 data for industrial firms registered with the Karachi Stock Exchange and these include both private and public firms. After computing a real profit rate (adjusted for inflation) for equity capital and a real interest rate for debt capital, he uses a weighting scheme between equity and debt capital to arrive at an initial estimate of $\mathrm{q}$. This $\mathrm{q}$ is then further adjusted for the divergence between market and shadow wages of labour and the social rates of return obtained on selected agricultural projects to obtain an economy-wide q.

None of the studies have yielded an estimate of the marginal productivity of public investment. SLD tried to assess public industrial investment but they compute an average return. The others do not restrict themselves to public investment and do not attempt to measure marginal productivity. A basic problem is that although the concept of marginal productivity of capital is clear enough, its estimation often raises very serious difficulties, as is apparent in the studies under review.

$\mathrm{q}$ is an important component of $\mathrm{v}$, the value of public income. Given the substantial differences in both the concept and measurement of $\mathrm{q}$, the estimates of $\mathrm{v}$ must also differ.

\section{The Value of $\mathbf{v}$}

In their Working Paper [6], Squire-Little-Durdag estimate v to be 1.25. They use the Household Income \& Expenditure Survey, 1971-72 [3] to determine distribution of households by income class, and consumption shares within each household category. They also use public expenditure data.
Guisinger has raised some fundamental objections to SLD's approach. An estimation of $\mathrm{v}$ should take into account both the tax incidence effect and the distributional impact of the transfer. The net transfer effect is the appropriate concept to measure, and to approximate this concept by looking only at the redistributional impact is inadequate. SLD look only at the redistributional impact. Furthermore, it is doubtful that the specific expenditures which SLD have analyzed to measure the value of public income are representative of the way the Government values public income vis- $a$-vis average private consumption. However, SG recognizes that the task of assessing every major expenditure will be formidable. This, coupled with the fact that no data on the incidence of Government taxes and revenues are available, makes the task impossible [1, p. 118].

The problems of estimating a realistic and usable $\mathrm{v}$ are discussed at length by Weiss [7]. He points out that the value of $v$ is very sensitive to the choice of CRI. The value can vary from 1.6 units to 6.7 units if CRI changes from 7.5 percent to 3 percent. The range is even wider: 1.6 to 45.3 if alternative assumptions of CRI, $\mathrm{q}$ and $\mathrm{s}$ are made [7,p. 157, Table 1].

A crucial parameter, $v$, is extremely sensitive to the value of CRI, which is a highly subjective parameter.

\section{The Value of ARI}

The resulting values of the ARI differ considerably from study to study because of the differences we have discussed above with respect to the computation of the CRI, q and $v$.

The following values have been estimated.

SLD : "Best" Estimate is set at 2 percent, although sensitivity analysis is carried out with a range of values, 2 percent -8 percent [5, p. 102];

SG : 7.3 percent -8.3 percent $[1$, p. 125]; and

ZK : 8 percent [2,p. 137].

The question is: which of the above estimates is the most appropriate for policy and project evaluation? The answer is: none. The reasons will be summarised below.

The SLD study is primarily an exercise illustrative of the use of shadow pricing in macroeconomic analysis. The authors have themselves cautioned against the use of these estimates [5, p. 111]. Guisinger's revision of the SLD estimates of q, however, does not measure the marginal productivity of public investment unless one assumes, as Guisinger does, that the returns on private and public investment do not differ by a large margin. ${ }^{2}$

${ }^{2}$ Since this is a crucial assumption, it has to be assessed critically. 
Khan's estimate of $\mathrm{q}$ is the weighted average of the marginal cost of 'new' funds (foreign loans and domestic savings) and the opportunity cost of funds withdrawn from other investments [2]. Since Khan's q refers to a different capital stock from that considered in the SLD and SG studies, it is strictly not comparable to the estimates in the latter studies. His q measures the productivity of capital investment on an economy-wide basis. If such a $\mathrm{q}$ is needed, the 1975-76 data used should be reviewed in the light of more recent data.

We have also pointed out that the value of $\mathrm{v}$ is undermined by its dependence on a highly subjective parameter, the CRI. Finally, the ARI necessarily suffers from the deficiencies in the estimation of $q$ and $v$.

\section{THE REMAINING PARAMETERS: THE CONVERSION FACTORS AND THE SHADOW WAGE RATE}

The alternative estimates of the Shadow Exchange Rate (SER), and the Consumption Conversion Factor (CCF or B) are reproduced below. They vary from 0.95 in the SLD study to 0.91 in the JW study and 0.98 in the ZK study. The differences are not substantial, but they all need revision because of the availability of more recent data. All these estimates are based on data from the early Seventies to the mid-Seventies. However, the extent and structure of protection have changed significantly since then, i.e. there has been a marked and steady shift away from export taxes to import revenues.

With respect to the CCF, the two sets of estimates, one from the SLD study and the other from the JW study, are strictly not comparable because they are applicable to different consumer groups. In the SLD study, 0.78 is for urban households, and 0.82 for rural households. In the JW study, his 0.98 applies only to unskilled labour in the lowest income category. The point is that the basket of consumption goods for which the CCF is being computed varies between estimates. Moreover, these estimates are based on the Household Income \& Expenditure Survey, 1971-72 [3]. More recent data are now available in the Micro-Nutrient Survey of Pakistan (1976-77) [4].

\section{The Shadow Wage of Labour}

Squire-Little-Durdag [5] present a short-run and long-run analysis of emigration while Khan [2] looks only at rural unskilled labour. So again, since two different types or categories of labour are being measured, the resulting estimates are not comparable. It seems pointless to determine which set is usable in view of the fact that up-to-date estimates of shadow wage will be available from an on-going study of labour migration from Pakistan to the Middle East. ${ }^{3}$

${ }^{3}$ The World Bank is financing a study entitled 'Labour Migration from Pakistan to the
. Middle East, 1973 - 83'. This study is being carried out by the Pakistan Institute of Development Economics, Islamabad (Pakistan).

\section{CONCLUSION}

The basic rationale for shadow pricing is that the results of the exercise help decision makers to allocate resources so as to further more efficient and socially more desirable uses of resources. It is doubtful that these studies can help decision makers along these difficult paths. A situation in which there are varying estimates for ostensibly the same parameter is confusing. In fact, it is hard to see how the situation can be otherwise when the underlying data are either too old or too patchy to serve as a sound basis for estimation.

In terms of further research, what would be most useful is an in-depth inquiry into the power and limitations of shadow pricing as an effective aid to decision making, given the data constraints which prevail in Pakistan and the realities of other factors which shape decision making in both policies and projects.

\section{REFERENCES}

1. Guisinger, Stephen. "Calculating Shadow Prices in Pakistan: Reflections on the Paper by Squire, Little and Durdag”. Pakistan Development Review. Vol. XVIII, No. 2. Summer 1979.

2. Khan, Muhammad Zubair. "Estimation of Shadow Prices for Project Evaluation in Pakistan”. Pakistan Development Review. Vol. XVIII, No. 2. Summer 1979.

3. Pakistan. Ministry of Finance, Planning and Development. Statistical Division. Household Income and Expenditure Survey, 1971-72. Karachi. 1973.

4. Pakistan. Planning and Development Division. Nutrition Cell. Micro-Nutrient Survey of Pakistan (1976-77). Vol. I. Islamabad. June 1978.

5. Squire, L., I. M. D. Little and M. Durdag. "Shadow Pricing and Macroeconomic Analysis: Some Illustrations from Pakistan". Pakistan Development Review. Vol. XVIII, No. 2. Summer 1979.

6. Squire, Lyn, I. M. D. Little and M. Durdag. "Application of Shadow Pricing to Country Economic Analysis with an Illustration from Pakistan". Washington, D. C. (USA): World Bank. n.d. (World Bank Staff Working Paper No. 330).

7. Weiss, John. "Project Selection and Equity Objective: The Use of Social Analysis”. Pakistan Development Review. Vol. XVIII, No. 2. Summer 1979. 